\title{
A DEFESA CULTURAL NO ÂMBITO DO DIREITO PENAL E PROCESSUAL PENAL: UMA VISÃO DO DIREITO COMPARADO COMO PARADIGMA PARA APLICAÇÃO NO DIREITO BRASILEIRO
}

\author{
Ionilton Pereira Do Vale ${ }^{1}$
}

\section{Resumo}

O direito à cultura, embora raramente encontrada explicitamente no ordenamento jurídico interno, é um direito fundamental que é garantido pelo direito internacional e encontra seu ponto mais forte formulação do artigo 27 do Pacto Internacional de Direitos Civis e Políticos, incorporando, assim os tratados acerca dos direitos humanos. $\mathrm{Na}$ Declaração Universal sobre a diversidade cultural, da Unesco, encontramos a afirmação da identidade cultural por cada povo, seja ele politicamente soberano ou não, seja uma grande potência ou não, que disponha plenamente de recursos e técnicas ou que esteja ainda em desenvolvimento, é o fundamento do pluralismo cultural. O reconhecimento e o respeito por tal pluralismo, à igualdade de direitos e à dignidade, aparecem hoje como um fator de paz e de compreensão entre as nações. A ideia de que o pluralismo cultural poderia ser a "essência mesma da identidade cultural" questiona a imagem tradicional de Estados, culturalmente monolíticos e introduz a noção de "cultura da mestiçagem", chegando-se à conclusão de que "a diversidade cultural dos povos deve ser considerada como fator de equilíbrio e não de divisão”. A Unesco, reconhece que a cultura adquire formas diversas através do tempo e do espaço. Essa diversidade se manifesta na originalidade e na pluralidade de identidades que caracterizam os grupos e as sociedades que compõem a humanidade. O presente artigo, trata da relação entre o direito à cultura e os aspectos relevantes da defesa cultural, tendo em vista, principalmente a doutrina e a jurisprudência já formada no Direito Internacional. O direito à cultura, é fonte de intercâmbios, de inovação e de criatividade, e a diversidade cultural é para o gênero humano, tão necessária como a diversidade biológica para a natureza.

Palavras-chave: Cultura. Defesa Cultural. Pluralismo Jurídico. Universalismo. Sociedade Multicultural. Tradição Cultural. Imigrantes. Migrações.

\section{INTRODUÇÃO}

Nas sociedades multiculturais contemporâneas, a relação entre crime e cultura assume contornos mais complexos e não necessariamente da mesma natureza daqueles que caracterizavam as discussões clássicas em torno das chamadas "subculturas desviantes". Essa relação pode agora envolver debates mais amplos tais como "direitos versus cultura" ou "universalismo versus relativismo". Contudo estas dicotomias nem sempre são o

\footnotetext{
${ }^{1}$ Mestre e doutorando em Direito pela Faculdade de Direito de Lisboa. Professor Universitário. Promotor de Justiça. Email: ionilton@uol.com.br.
} 
prisma mais adequado para situar a tensão que pode existir entre a indivisibilidade jurídica do Estado e a (alguma) diferença cultural. ${ }^{2}$

Quando os imigrantes e refugiados travam conhecimento com um novo país, eles carregam com eles, tanto suas tradições culturais, como suas tradições jurídicas. Estas tradições jurídicas são comumente referidas como direito consuetudinário. A confluência resultante do direito consuetudinário (o costume ou tradição) e as leis, que já estão presentes no novo país é conhecido como o pluralismo jurídico. O pluralismo jurídico pode ser distinguido do pluralismo cultural, embora a primeira seja obviamente baseada na lei. Não pode haver diversas tradições jurídicas, sem diversas tradições culturais, mas a conexão entre as duas é muitas vezes das mais sutis. Existem costumes dos mais diversos, envolvendo inclusive o uso da mesma língua. $\mathrm{Na}$ língua portuguesa, por exemplo, a palavra rapariga, tem um sentido, quando pronunciado em Portugal, no Brasil, contudo, em especial no Nordeste, tem um sentido mais pejorativo. ${ }^{3}$

\section{A RELEVÂNCIA DOS COSTUMES E A DEFESA CULTURAL}

Uma pergunta relevante, se traduz da seguinte forma: Quando é que o costume pode sair fora da lei e começar a ser crime? Por exemplo, é comum apertar as mãos na cultura ocidental, quando somos apresentados a uma outra pessoa. Embora seja considerado indelicado não oferecer a mão em uma apresentação, esta omissão ritual, não é legal e necessáriamente exigida. Contudo, em alguns grupos minoritários, o adultério pode ensejar a prática de homicídio, o casamento, o rapto não consensual ou relações sexuais com menores. O Direito Penal, mais do que outros setores do Direito, apresenta a característica de ser uma lei local, criado no âmbito de um determinado Estado, de modo que cada em cada Estado individual existe um determinado sistema jurídico penal.

Conforme, Otfried Höffe, o Direito Penal moderno nas sociedades multiculturais e globalizadas, está hoje quase que exclusivamente da competência individual dos Estados-Membros. ${ }^{4}$ Em cada Estado, de fato, encontramos um catálogo especial de delitos punidos com penas determinadas e sujeito a certas regras da parte geral, que pode assemelhar-se mais ou menos extensa, mas quase nunca coincidem com o disposto em outros Estados, com o resultado de que "o que é crime aqui, pode não ser em outro lugar, ou vice-versa. É neste ponto, que se situa, a defesa cultural. As grandes migrações a partir do século XIX, fizeram, com que povos de uma determinada nação, procurassem abrigo, trabalho e desenvolvimento, que não obtinham em seus países de origem. Nesta viagem os imigrantes, levaram os seus costumes como assinalado, na forma de um certo "direito consuetudinário", e ao praticá-los, os Tribunais devem optar ou não em levar em conta estas tradições culturais.

\footnotetext{
${ }^{2}$ RENTELN, Alison Dundes. The Cultural defense. New York: Oxford University Press, 2004.

${ }^{3}$ Cf a proposito as acepções da palavra no dicionário Michaellis de Língua Portuguesa: 1 Feminino de rapaz. 2. Mulher nova; moça. 3. Mulher no início da adolescência, ou no decurso dessa idade. 4. Moça do campo; moça rústica. $5 \mathrm{~V}$ donzela. 6 pej $\mathrm{O}$ mesmo que amásia, concubina, meretriz. Aum: raparigaça, raparigão, raparigona.

${ }^{4}$ Otfried HÖFFE, Globalizzazione e diritto penale. Torino, Edizioni di Comunità (Territori di Comunità, 24), 2001, p.64. vol.08, nº. 02, Rio de Janeiro, 2015. Pp. 758-773 
Sendo razoável e apresentando a verossimilhança, que possam existir nestes casos, os Tribunais devem levar em conta a defesa cultural. Mas como seria identificado um caso cultural? E em que medida um juiz ou tribunal pode ser influenciado pela defesa cultural? A este respeito, Renteln entende que uma vez evidenciado o contexto das relações culturais, deve-se conceder, o direito aos litigantes, de apresentar a evidência na corte a respeito das tradições que são importantes para a manutenção de sua identidade cultural. A festejada autora, propõe a seguir um teste para verificar os verdadeiros pressupostos da defesa da cultura, que é realizado a partir de uma fórmula, contendo três perguntas: 1 . O litigante é um membro do grupo étnico?; 2 .O grupo tem uma tradição como aquela reivindicada pelo litigante?; 3 .O litigante foi influenciado por essa tradição quando agiu? ${ }^{5}$

Tendo em conta que os indivíduos são psicologicamente predispostos a agir em conformidade com as normas e preceitos de sua cultura, é necessário, no caso, que a justiça exija, que as provas culturais sejam admitidas no tribunal. Isto não quer dizer que uma pessoa deve ser sempre considerada inimputável ou semi-imputável com base na sua cultura. No entanto, ignorar a verdade de um processo de aculturação é distorcer o resultado do processo desde início do julgamento.

Isto significa, que não só a prova cultural deve ser admitida no tribunal, mas também que a lógica cultural deve ser levada a sério. Infelizmente, simplesmente não é possível dizer com precisão quanto o peso da relevância da cultura deve ser conferido nos casos examinados. Como um princípio geral, pode-se dizer que quando a defesa cultural, pode ser mostrado como uma verdade, então a cultura deverá afetar a disposição do caso, a menos que resulte em danos irreparáveis para os outros. Na ausência de qualquer ameaça real, as minorias étnicas devem, em geral, ter o direito de seguir as suas tradições culturais, livre de qualquer interferência governamental.

De acordo com Basile, o reconhecimento da diversidade cultural do "outro" nunca foi, nem nunca será absoluta e incondicional, mas exige a colocação de limites e tolerância, marcados pelo respeito aos direitos humanos fundamentais. Limites também muito essenciais nas áreas abrangidas pela lei penal, que é, de fato, a zona da fronteira para o reconhecimento da diversidade cultural. Nesta área, portanto, será necessário proceder com extrema cautela, para evitar invasões perniciosas que correria o risco de resultar em uma espécie de legitimidade (ou atenuação desta) da violação dos direitos fundamentais. ${ }^{6}$

Um exemplo bem-sucedido de defesa cultural, foi o caso Dong Lu Chen, um homem chinês nascido em Nova York, que espancou sua esposa até a morte depois desta ter confessado o adultério. A atenuação da pena teria sido impossível, sem o depoimento de Burton Pasternak, professor da antropologia no Hunter College, que testemunhou que mulheres na China são por vezes severamente punida por adultério. Ele disse que o adultério é visto como uma enorme "mancha" que reflete não apenas sobre o marido, mas "é uma reflexão sobre seus

\footnotetext{
${ }^{5}$ RENTELN, Alison Dundes. The Cultural defense, cit., pag. 87.

${ }^{6}$ BASILE, Fábio. Imigrazioni e reati culturalmente motivati. il diritto penale nelle società multicultural.Milano: Giuffrè Editore 2010, p.9.
} 
antepassados e seus descendentes." O Tribunal de Justiça levou em consideração, o depoimento de Pasternak, quando condenou Chen, em homicídio de segundo grau e decidiu condená-lo a apenas cinco anos de liberdade condicional. Esta frase "cinco anos de liberdade condicional", essencialmente representa uma defesa completa, em vez de simples mitigação.

As organizações de mulheres, grupos asiáticos americanos, chegaram a condenar a decisão, e ainda apresentaram uma reclamação no Estado de Nova Iorque, junto à Comissão de Conduta Judicial pedindo uma investigação sobre a decisão do juiz. Contudo, a decisão se manteve em seus próprios fundamentos.?

Mutatis mutandis, o argumento da defesa cultural poderá soar ridículos aos juízes, se evidentemente não tiver qualquer relação com a cultura de um povo.

Destaca-se o caso Lakireddy, imigrante indiano, que se declarou culpado de quatro acusações, incluindo tráfico de adolescentes para os Estados Unidos, para efeitos do sexo e da mão de obra barata. Os crimes cometidos pelo indiano, nada tinham a ver com a cultura, em que pese ainda o fato do acusado ter vivido 40 anos nos Estados Unidos, fato este que que pesou na decisão dos juízes. ${ }^{8}$

Acordão paradigmático neste sentido foi o processo 1,11. - 200.827, oriundo da Suprema Corte italiana, que tratou de um caso específico de defesa cultural, em que um imigrante marroquino foi condenado pelos tribunais responsáveis pelos crimes de abuso em família, sequestro, violência sexual contra a mulher e violação das obrigações do apoio da família, contra a esposa e os filhos menores. ${ }^{9}$

Com um recurso de cassação, ele argui a falta de motivação na decisão impugnada, com o escopo da descoberta do elemento subjetivo em suas ações: na sua opinião, na verdade, os tribunais inferiores teriam sofrido uma polarização "etnocêntrica" em avaliar as relações e as relações sócio emocionais entre cônjuges, bem como as relações económicas entre pais e filhos, relevantes para a decisão do caso, uma vez que "aplicam-se os esquemas de avaliação típico da cultura ocidental, sem levar em conta as necessidades de integração racial e sem pesar, no comportamento do agressor, um cidadão marroquino, a diversidade cultural e religiosa que tem caracterizado e esclarecido, finalisticamente, as ações que ele fez e acredita-se ser ilegal." 10

O Supremo Tribunal Italiano, no entanto, rejeita o recurso com base no seguinte argumento: "a hipótese de defesa, de que (...) o elemento subjetivo do crime em questão seriam excluídos do conceito, em face de que o acusado, como um cidadão da religião muçulmana, tem da vida familiar e do poder marital, e como chefe da família (um conceito completamente diferente do modelo e a concepção atual do Estado italiano),não é

\footnotetext{
${ }^{7}$ Renteln, Alison Dundes. The Cultural defense, cit., pag.134.

${ }^{8}$ Disponível em: http://sfpublicpress.org/news/2012-02/ how-an- infamous- Berkeley - human-trafficking- case-f ueled- reform. Acesso em 22 de janeiro de 2014.

9 BASILE, Fábio.Imigrazioni e reati culturalmente motivati. il diritto penale nelle società multicultural.Milano:GIUFFRÈ EDITORE 2010, p.56.

${ }^{10}$ BASILE, Fábio.Imigrazioni e reati culturalmente motivati. il diritto penale nelle società multicultural, cit, p.86. vol.08, nº. 02, Rio de Janeiro, 2015. Pp. 758-773 
admissível por qualquer forma, porque coloca contrária, de forma absoluta às regras de cardeais que informam e são baseados o Estado Italiano, os Códigos de prática jurídica e regulamentos interpessoais, nos seus artigos. 2 o e 3 o da Constituição "Estes princípios", prossegue a Corte de Cassação, "É, de fato, uma barreira intransponível contra a introdução de direito e de fato, na sociedade civil, de costumes, práticas e tradições que seriam "antihistórico" em face dos resultados obtidos durante os séculos, para fazer a afirmação dos direitos invioláveis da pessoa, cidadão estrangeiro. Qualquer consideração pelos acusados, de fatos criminosos praticados por ele como "inofensivas ou socialmente úteis ou não repreensíveis" não pode ser utilizado para fins de exclusão de dolo ou a afirmação de ignorância inevitável do direito penal, o Tribunal concluiu, que a defesa cultural, apenas pode servir "sob múltiplas variáveis para customização e adequação da sentença em face do artigo 133 do CP". ${ }^{11}$

Um caso histórico em matéria de jurisdição do governo federal sobre tribos indígenas, surgiram de disputas tribais sobre a adesão, pode explicar a influência da cultura nas decisões estatais. Uma mulher da tribo Pueblo Santa Clara se casou com um Navajo e teve sete filhos. O chefe da tribo Santa Clara Pueblo negou filiação aos filhos da mulher com base em uma ordenança tribal, que excluía as crianças de sexo feminino, mas não do sexo masculino, aos membros que casassem fora da tribo. Note-se, que as crianças excluídas não poderiam votar ou ocupar cargos seculares, permanecer na reserva em caso de morte da mãe, nem herdar a casa de sua mãe ou terras comunais. A mãe pediu à corte de distrito federal anular a execução a ordenança tribal. O Tribunal Distrital decidiu em favor da mãe, alegando que a decisão violava Título I do Indian Civil Rights Act de 1968 (ICRA), 25 USC 1301-1303, que prevê que "uma tribo de índios no exercício da função de autogoverno pode negar a qualquer pessoa sob sua jurisdição a igual proteção das leis". Citando precedentes ${ }^{12}$, a Suprema Corte do Estados Unidos, manteve a decisão tribal, declarando que as tribos indígenas têm sido reconhecidas como possuidores de imunidades, e que este aspecto da soberania tribal, como todos os outros, está sujeito ao controle superior e plenário do Congresso. Mas "sem autorização do Congresso," as nações "indígenas estão isentas de controle". ${ }^{3}$

\section{A DEFESA CULTURAL NA AMÉRICA DO SUL: O CASO BOLIVIANO E BRASILEIRO}

Na Bolívia a comissão de reforma integral do Código Penal da Bolívia integrada por consultores internacionais, tem como proposta agregar ao Código, dispositivos acerca da justiça comunitária, e do pluralismo cultural, utilizando-se da experiência europeia, em relação a justiça comunitária e ao reconhecimento de

\footnotetext{
${ }^{11}$ BASILE, Fábio.Imigrazioni e reati culturalmente motivati. il diritto penale nelle società multicultural, cit.p. 87.

${ }^{12}$ Indian tribes have long been recognized as possessing the common-law immunity from suit traditionally enjoyed by sovereign powers. Turner v. United States, 248 U.S. 354, 358 (1919); United States v. United States Fidelity \& Guaranty Co., 309 U.S. 506, 512 -513 (1940); Puyallup Tribe v. Washington Dept. of Game, 433 U.S. 165, 172 -173 (1977). This aspect of tribal sovereignty, like all others, is subject to the superior and plenary control of Congress. But "without congressional authorization," the "Indian Nations are exempt from suit." United States v. United States Fidelity \& Guaranty Co., supra, at 512.

${ }^{13}$ Santa Clara Pueblo v. Martinez, 436 E.U. 49 (1978).
} 
pluralismo cultural. ${ }^{14}$ Destacam os autores, e entre estes, o jurista Eugenio Raúl Zaffaroni, que este capítulo é de fundamental importância e tem como resultado sentar bases claras, para o reconhecimento do pluralismo cultural, que provêm de um elemento de direitos humanos de primeiríssima hierarquia, (a respeito da própria cultura), mas que não pode lesionar outros direitos humanos fundamentais, no que constitui um difícil equilíbrio que a lei deve preservar. A elaboração de um completo capítulo de previsões, si se logra perfeito, pode resultar exemplar em toda a região. ${ }^{15}$

Observe-se por fim, que ao lado do direito à cultura e seu correspondente da defesa cultural, existem diversas convenções assumidas pelos países signatários, de proteção às crianças e às mulheres, como a Convenção Sobre a Eliminação de todas as Formas de Discriminação contra a Mulher (1979-ONU); Convenção sobre os Direitos da Criança (1989-ONU) e no sistema regional: Convenção Interamericana para Prevenir, Punir e Erradicar a Violência Contra a Mulher (1994-OEA).

No Brasil atualmente é grande a imigração oriunda de países pobres como o Haiti e o Senegal, bem como os vizinhos, que fazem fronteira com o Brasil, como Bolívia, Chile, Peru e equador, e são transportados por

\footnotetext{
${ }^{14} \mathrm{~A}$ este respecto, los problemas que se plantean son diversos, por lo que sería conveniente analizar las siguientes situaciones:(a) Sanciones impuestas por la comunidad que no repugnan a los Derechos Humanos: en tales casos, cabe prescindir de todo ejercicio de poder punitivo por parte del estado, siempre que la sanción aparezca como proporcional a la gravedad del hecho. Si no lo fuere, el juez valorará lo más conveniente para la paz social en el caso concreto, pero nunca impondrá una pena sin tener en cuenta -y por consiguiente moderar la que imponga- que la persona ya ha sufrido una pena, aunque sea inadecuada por insuficiente;(b) Sanciones impuestas por la comunidad que no sean aceptables conforme a los Derechos Humanos, como azotes y otros maltratos físicos o morales: en tales casos, serán otros órganos del estado los encargados de procurar la desaparición de estas penas comunitarias, pero dado que la persona ya la habría sufrido, el juez no podrá imponerle una nueva pena (violaría la prohibición de doble punición), salvo que considere insuficiente la sufrida y con la advertencia de la hipótesis anterior;(c) Conductas no prohibidas conforme a la cultura comunitaria: en tanto la atipicidad de la conducta no resulte violatoria de Derechos Humanos por insuficiente tutela, los jueces se abstendrán de imponer penas y la conducta se considerará atíicica en el caso concreto (los casos más comunes que se plantean en otros países son los hurtos campestres y las inhumaciones clandestinas). Si la conducta afectase a terceros ajenos a la comunidad y a la cultura del grupo, el juez procurará soluciones reparadoras; (d) Cuando la atipicidad afecte Derechos Humanos o resulte gravemente discriminatoria (casos de estupro, iniciación sexual de adolescentes o niñas, otras discriminaciones), deberá preverse el error de comprensión o error de prohibición culturalmente condicionado, estableciendo en cada caso su grado de vencibilidad. El juez podría disponer, en caso de gravedad (sea el error vencible o invencible) una pena consistente en la adecuada instrucción del infractor acerca de la naturaleza de su conducta. El juez podría también ordenar al Poder Ejecutivo una acción de concientización de la comunidade;(e) Del mismo modo se procederá cuando el error culturalmente condicionado fuese de tipo. Esta previsión es particularmente significativa en cuanto a la aplicación de supuestos métodos de curación:(f) Conductas penadas por la comunidad pero que son atípicas para la ley penal. El juez sólo intervendrá cuando la prohibición resulte repugnante a los derechos humanos o gravemente discriminatoria (persecución infamante de la mujer considerada adúltera, castigos a homosexuales), evaluando en cada caso si se ha incurrido en una error de comprensión y, en tal caso, procederá como se ha indicado antes.(g) Supuestos de penas comunitarias por conductas mágicas o agresiones imaginarias: es uno de los problemas más serios que se plantean en la diversidad cultural, con diferentes concepciones del mundo (caza de brujos y liberaciones del diablo con resultados lesivos o letales) y, por ende, de la causalidad. Cada caso debe ser analizado en particular y no puede resolverse sólo con penas, pues requiere una cuidadosa intervención en la comunidad que debe respetar la concepción del mundo propia de ésta, pero al mismo tiempo prevenir estas consecuencias. El juez debe disponer de una gama de medios para intervenir y no sólo de la pena. (h) Es digna de analizarse la posibilidad de constituir un órgano asesor permanente de los tribunales máximos para los casos más conflictivos que pueda plantear el pluralismo cultural y que deban ser resueltos por éstos o respecto de los cuales éstos deban sentar criterios jurisprudenciales, in: ZAFFARONI, Raúl Eugenio et al. Criminalidad, evolución del derecho penal y crítica al derecho penal en la acutalidad. Buenos Aires: Del Puerto, 2009.p.32.

${ }^{15}$ ZAFFARONI, Raúl Eugenio et al. Criminalidad, evolución del derecho penal y crítica al derecho penal en la acutalidad. Buenos Aires: Del Puerto, 2009.p.13.
} 
"Coiotes", que cobram até $\mathrm{R} \$ 4.000,00$ (quatro mil reais). ${ }^{16}$ Estes imigrantes certamente poderão fazer eventual uso no Brasil da Defesa Cultural.

O Supremo Tribunal Federal, já se debruçou com caso envolvendo a defesa cultural. Era essa a questão que estava em jogo no caso da "Farra do Boi". De um lado, vários grupos defendiam que o evento chamado "farra do boi" fazia parta da cultura popular em Santa Catarina e, por isso, merecia ser mantido. Do outro lado, diversos grupos defendiam que a "farra do boi" gerava crueldade desnecessária aos animais, devendo, portanto, ser proibida.

O caso chegou até o Supremo Tribunal Federal que, em célebre e elogiável decisão, determinou que o Estado de Santa Catarina adotasse as providências necessárias para proibir a chamada "farra do boi". Veja a ementa:

COSTUME - MANIFESTAÇÃO CULTURAL - ESTÍMULO RAZOABILIDADE - PRESERVAÇÃO DA FAUNA E DA FLORA ANIMAIS - CRUELDADE. A obrigação de o Estado garantir a todos o pleno exercício dos direitos culturais, incentivando a valorização e a difusão das manifestações, não prescinde da observância da norma do inc. VII do art. 225 da Constituição Federal, no que veda a prática que acabe por submeter os animais à crueldade. Procedimento discrepante da norma constitucional denominada 'farra do boi' (STF, RE 153541-1-SC, rel. p/ acórdão Min. Marco Aurélio).

\section{AS RELAÇÕES SEXUAiS E O CASAMENTO NO CONTEXTO DA DEFESA CULTURAL}

Existem diferentes concepções culturais do casamento. Em algumas sociedades o casamento é com base na escolha individual de um companheiro, e depende de amor ou apego romântico. Em outros, um casamento é concebido para permitir uma aliança entre os grupos. No caso de imigrantes e refugiados, os rituais do casamento exigidos em seus países de origem com base em um grupo étnico, muitas vezes entram em conflitos com a lei da nova nação.

Uma das motivações que os pais têm para casar suas filhas em tenra idade é assegurar a sua virtude. Se os pais esperarem muito tempo, há um risco maior que as meninas não sejam consideradas aptas para o casamento aos olhos de sua comunidade.

Sociedades têm diferentes regras que especificam a idade adequada para o casamento, e métodos adequados para se casar, o número de parceiros admissíveis ao casamento, as maneiras de se divorciar e casar novamente, e os princípios que regem a custódia da criança.

A Convenção das Nações Unidas (ONU) sobre os Direitos da Criança define criança como uma pessoa menor de 18 anos, a menos que a maioridade seja legalmente alcançada mais cedo nos termos da legislação

16 Disponível em: http://wwwl.folha.uol.com.br/fsp/mercado/24069-brasil-recebe-57-mais-mao-de-obraestrangeira.shtml.Acesso em 20 de fevereiro de 2014. 
pertinente do país. Portanto, com algumas exceções, "casamentos de crianças" são geralmente entendidos como casamentos que acontecem antes dos 18 anos. ${ }^{17}$

Enquanto a maioria dos casos, podem ser classificados como direito de família, envolvendo questões de direito, como por exemplo, o casamento, o divórcio, a guarda da criança, os litígios envolvendo casos culturais, são tratados como matéria penal. Por exemplo, se uma homem casa com mais de uma mulher, nas jurisdições em que a monogamia é uma prática padrão, teríamos em tese, o crime de bigamia. Também, em alguns casos, pode envolver estupro, sequestro, cárcere privado, e assim por diante. ${ }^{18}$

Sempre são feitas exceções aos estatutos legais para as leis religiosas ou práticas comuns. No Níger, por exemplo, o código civil proíbe que os meninos se casem com menos de 18 anos e as meninas com menos de 15 . Segundo observadores, o código "praticamente nunca é aplicado" por causa da existência de dois outros sistemas legais, um judicial e outro islâmico, que permite o casamento com menos idade. ${ }^{19}$

As sociedades que tenham estabelecido uma idade mínima para o casamento, como a Reino Unido e os Estados Unidos no início do século XX, tem como preocupação primária, o casamento infantil, que podem resultar em consequências desastrosas.

A primeira consequência indesejada, mas que pode ser visto como um motor primário, é que a criança não tem capacidade de escolher, então o casamento irá violar o indivíduo em sua capacidade de decisão. Em segundo lugar, as meninas que se casam, terão menor probabilidade de completar a sua educação formal. Por fim, e em terceiro lugar, os casamentos de noivas adolescentes, mais frequentemente resultam em divórcio, que são socialmente indesejáveis.

O leadin case Alhaji Mohamed V. Knott, julgado em 1969, ilustra bem a dificuldade dos juízes, em lidar com legislações conflitantes sobre casamento.

Alhaji Mohamed, um muçulmano de 26 anos, da Nigéria, tinha recebido em casamento, na Nigéria, uma menina de 13 anos de idade, Rabi Mohamed Musi. Ambos eram muçulmanos pertencentes à tribo Hauçá e domiciliados na Nigéria onde o casamento foi celebrado e considerado válido de acordo com a lei nigeriana. Além de polígamo, segundo informa o acordão, Rabi Mohamed Musi, não tinha a idade legal, para o casamento, segundo as leis do ocidente. Em abril de 1967, eles se mudaram para a Inglaterra, onde o homem foi completar seus estudos, tendo o caso chegado ao conhecimento da polícia depois que este, visitou um médico em Londres,

\footnotetext{
${ }^{17}$ ARTIGO 1: Para efeitos da presente Convenção considera-se como criança todo ser humano com menos de dezoito anos de idade, a não ser que, em conformidade com a lei aplicável à criança, a maioridade seja alcançada antes.

18 BRONITT, Simon. Visions of a Multicultural criminal law: an Australian perspective. In: Multicultural jurisprudence. Comparative perspectives on the cultural defense. FOBLETS, Marie-Claire; RENTEELN, Alison Dundes (Ed). Oregon: Oxford and Portandle, 2009, p.34.

${ }^{19}$ Disponível em: MELCHIORRE, Angela. 2004. At what age are schoolchildren employed, married and taken to court? 2a ed. Copenhagen: The Right to Education Project. http://www.right-toeducation.org/content/age/index.html. Acesso em 5 de março de 2014.
} 
para tratamento de doenças venéreas, e trouxe com ele a menina, a quem apresentou como sua esposa. Ela foi retirada de sua casa, cinco meses após a sua chegada, por um despacho do Norte Southwark, o Tribunal de Menores. Uma policial feminina chamada Knott apresentou uma denúncia nas secções 2 e 62 do Estatuto da Criança e adolescente de 1933 (Children and Young Person's Act of 1963), alegando que a menina, não estava recebendo cuidados, proteção, e orientação e foi exposta ao perigo moral.

Os juízes do Southwark North Juvenile Court concluíram que, como o casamento era potencialmente poligâmico, não deveria ser reconhecido como válido pela lei inglesa. Os juízes do tribunal de menores, horrorizados com o comportamento promíscuo do homem, entenderam que a denúncia foi comprovada pelos fatos. A menina estava condenada a ficar em uma instituição como "uma pessoa em formação." A decisão foi tomada com base em dois fundamentos: primeiro, sendo o casamento potencialmente poligâmico, ele não poderia ser reconhecido na Inglaterra, e na ausência de casamento, ela foi exposta ao perigo moral no relacionamento. Segundo, mesmo se o casamento fosse válido, seria errado deixar a menina em tal circunstância: Concluem os juízes do Tribunal de Menores: "Em nossa opinião, a continuação de tal associação, não obstante o casamento, seria repugnante para qualquer inglês decente, homem ou mulher. Nossa decisão reflete a repugnância."

O recurso do homem para o Tribunal Divisional teve êxito. O tribunal considerou que o fato do casamento ser potencialmente poligâmico não implicava necessariamente, que este não poderia ser reconhecido na Inglaterra. O fato é que a menor, era uma mulher tanto na Inglaterra quanto na Nigéria.

O tribunal decidiu também que, não havia motivos para manter qualquer restrição em relação à menina, que poderia ficar em uma instituição para pessoas em formação. A fonte da confusão foi a existência de uma lei acerca dos delitos sexuais, o Act de 1956, que proibia relações sexuais com meninas menores de dezesseis anos de idade. Mas o Tribunal de Justiça decidiu, que a relação sexual dentro do casamento é legal, não importa a idade do cônjuge. Um dos juízes, Lord Parker, rejeitou completamente a visão de primeira instância que a relação era ofensiva. Citando Baindail v Baindail, (1946) o juiz, Lord Parker afirmou que o casamento foi válido mesmo sendo reconhecidamente poligâmico. Ele também rejeitou a ideia de que a menina estava em perigo moral, argumentando que era inadequado, entender o que seria repugnante para um homem inglês, ante a relatividade da cultura. "Eu não posso me valer do modo de vida inglês, percebendo o modo de vida em que esta menina foi educada, e inevitavelmente dizer que isso é repugnante. É, certamente natural para uma menina se casar com essa idade. Elas se desenvolvem mais cedo, e não há nada de abominável em seu modo de vida, razão pela qual, uma menina de 13 anos pode se casar com um homem de 25 anos.

A lei de imigração Inglesa foi alterada em 1986, para que as noivas menores de dezesseis anos, pudessem entrar no Reino Unido, delimitando em dezesseis anos, a idade mínima para o consentimento em relações sexuais 
lícitas e para o casamento, em um retrocesso legal, no ano de 2008, aumentaram para 21 anos a idade legal para o casamento, para que o visto de casamento seja mantido no Reino Unido. Esta alteração nas condições mínimas para aplicação do visto de casamento, faz parte de um plano maior que modifica substancialmente o sistema imigratório do Reino Unido. O Plano divulgado pelo governo britânico à época, é considerado a maior modificação e inovação nas leis imigratórias dos últimos 45 anos. Contudo, a Suprema Corte do Reino Unido derrubou lei que impedia que estrangeiros menores de 21 anos ou casados com menores de 21 anos tivessem o direito de morar no país. ${ }^{20}$

Grande parte do debate sobre o casamento nas relações culturais, vai de encontro à noção de escolha e livre arbítrio dos indivíduos, em especial das pessoas do sexo feminino, a quem é muitas vezes é imposto o jugo de um casamento desigual. O casamento envolvendo o pluriculturalismo tem como objetivo, forjar uma aliança entre os grupos. Os opositores do casamento com mulheres menores de idade e incapazes, pressupõe a infelicidade em seus casamentos.

Toda a discussão também presume que não há uma distinção clara entre infância e a idade adulta. $\mathrm{O}$ fato é que com a modernidade (ou melhor, a pós- modernidade), as crianças vão atingindo a puberdade em uma etapa cada vez mais precoce de suas vidas. Acresce-se a isto outros fatores, presentes no cotidiano pós-moderno, tais como a mídia, em especial a internet, que amplia o espaço de comunicação, a globalização, que leva os jovens a intercâmbios culturais cada vez mais cedo.

O fato, é que o casamento assim concebido pode implicar (e quase sempre implica), em situações que migram do direito civil, para o direito penal, traduzindo-se muitas vezes em coação, abuso de poder, sequestro, cárcere privado e muitas vezes até em homicídio.

Uma situação emblemática, é citada por Fábio Basile, entre outros numerosos casos, envolvendo a instituição do casamento, dentro das relações culturais. ${ }^{21}$

O caso reportado, se deu na Alemanha, onde réu e vítima são, respectivamente, uma jovem e um jovem curdo, incluindo os seus primos, ambos pertencentes à comunidade Yazidi religiosa (uma corrente cismática do Islão entre os curdos) e ambos imigrantes na Alemanha com suas famílias e que vivem com eles no momento dos fatos. De acordo com as intenções da sua família, os dois jovens celebraram noivado em junho de 2005, comemorado com uma grande festa com mais de duzentos convidados. A menina, no entanto, já tem um segredo, que é outro namorado, e depois, meses mais tarde, encontra um pretexto para quebrar o noivado. Em uma tentativa de salvar o compromisso, e "salvar" a promessa do casamento, o noivo ajudado por um irmão e um primo, então decide raptar a jovem, que é mantida sob estreita vigilância durante várias horas, durante o qual o

\footnotetext{
20 Disponível em: http://www.conjur.com.br/2011-out-13/cai-lei-britanica-restringia-imigracao-combater-casamentoforcado.Acesso em 10 de janeiro de 2014.

${ }^{21}$ Processo 2.5. - Bundesgerichtshof 1 de fevereiro 200742a
} 
acusado fica a fazer-lhe ameaças. A jovem, assustada, no fim, diz estar pronto para se casar com o réu, que, no entanto, neste momento pede um "teste" de disponibilidade, que consiste na consumação de um ato sexual simbolizado na tradição de sua comunidade religiosa, na folha do tálamo, como um sinal tangível da união dos dois.

Depois das relações sexuais, a jovem é socorrida por seus familiares, contudo, o acusado mostra que a folha surtiu o efeito desejado. Os parentes da jovem, congratulam os nubentes, pois agora, do seu ponto de vista, o casamento é inevitável.

A menina, jovem, entretanto, relata os fatos, ao seu namorado, que delata o caso à polícia. O acusado é condenado pelo tribunal de primeira instância, por sequestro e violência sexual, a uma pena por demais branda, que é suspensa condicionalmente, dois anos de prisão.

O Bundesgerichtshof (BGH), embora reconhecendo que a pena aplicada é muito suave, rejeita recurso do Ministério Público que invocou uma pena mais severa, considerando que o tribunal poderia avaliar, em favor dos acusados, entre outros, também os seguintes circunstâncias: com sua conduta o acusado fê-lo, a fim de atender a expectativa de um iminente casamento, tendo em vista que as famílias dos dois jovens tinham trocados promessas solenes, durante a cerimônia oficial de noivado, de modo que a "verdadeira autoridade moral" de comportamento ilícito não era ele, mas sua família, que o tinha pressionado nesse sentido, tanto que ele nem mesmo foi buscar seu próprio prazer sexual em ofender sexualmente a vítima, fato confirmado pela palavra da vítima.

O tribunal de julgamento, portanto, "tinha o direito, com a finalidade de atenuação da pena, o fato de que os acusados - assim como a vítima - vem de outro ambiente cultural (aus einem anderen Kulturkreis), de forma que o acusado estava sob pressão, em relação às expectativas de sua família e, portanto, teve de superar um inibidor limiar inferior (eine geringe Hemmenschwelle) para o cometimento do delito.

\section{A CULPABILIDADE NO CONTEXTO DAS RELAÇÕES CULTURAIS: UMA POSSIVEL JUSTIFICATIVA}

\section{Culpabilidade e inimputabilidade}

Um dos elementos do crime é exatamente a culpabilidade,visto que não pode haver crime sem culpa, ao adotarmos a teoria tripartida de crime, sendo o juízo de reprovação pessoal que se realiza sobre a conduta típica e ilícita praticada pelo agente.

Nas lições de Welzel, "culpabilidade é a 'reprovabilidade' da configuração da vontade. Toda culpabilidade é, segundo isso, 'culpabilidade de vontade'. Somente aquilo a respeito do qual o homem pode algo 
voluntariamente lhe pode ser reprovado como culpabilidade".22 Por seu turno Cury Urzúa,define a culpabilidade a reprovabilidade do fato típico e antijurídico, fundada em que seu autor o executou não obstante que na situação concreta podia submeter-se às determinações e proibições do direito". ${ }^{23}$

O princípio de culpabilidade liga-se a uma concepção do homem como pessoa, ou seja, como ente dotado de capacidade de decidir acerca da conduta a ser realizada. Só a partir desse nível pode-se realizar um juízo de reprovabilidade, pois, o princípio de culpabilidade tem como pressuposto lógico a liberdade de vontade do homem, como afirma Jescheck. Disto resulta que, quando o direito se dirige a uma pessoa para fazer incidir sobre sua conduta um juízo de reprovação, é porque the reconhece esse caráter de ente responsável, ou seja, a livre determinação da vontade humana é pressuposto lógico e necessário do princípio de culpabilidade. Só dessa maneira se pode visualizar o homem, ou seja, se pode vê-lo de pés no chão, dotado de defeitos e virtudes, tal qual o criou a natureza, para que se possa cogitar de um juízo de reprovação. ${ }^{24}$

Esta censura pessoal é elemento da punição do autor do fato ilicito, que pode ser afastada pela inimputabilidade, que no Código Penal Português, está alojado no artigo $19^{\circ}$ e $20^{\circ}$, no Código Penal Brasileiro, em seu art 21, e no Código Penal alemão em seu art.20.

O princípio da inexistência de pena sem culpabilidade constitui uma das bases do Direito Penal moderno. Não obstante, ele é ainda hoje, pouco mais que uma meta a ser alcançada, pois, ainda proliferam pelas legislações os delitos qualificados pelo resultado e os chamados de delitos de mera suspeita, que são negação do princípio. 25

No que tange a inimputabilidade, o terreno é menos arenoso, que a potencial consciência da ilicitude, que examinaremos, bem como as causas supralegais de excludente da ilicitude. Não há que se falar por inimputabilidade, por razões culturais,embora eventualmente esta possa servir de lastro para eventual defesa, com basa na tradição e na cultura. ${ }^{26}$

\section{A consciência potencial da ilicitude:o erro de proibição como defesa cultural}

O erro de proibição encontar-se, em quase todas as legislações penais. No Código Penal alemão tem previsão no $\$ 17^{27}$ na legislação portuguesa no artigo 16 do Código Penal português, e na legislação brasileira no artigo 21 do Código Penal brasileiro.

\footnotetext{
${ }^{22}$ WELZEL, Hans. Derecho penal alemão.trad.Juan Bustos Ramirez e Sergio Yanes Peréz.Chile: Juridica de Chile,1987, p167.

${ }^{23}$ CURI ÚRZÚA. Enrique. Derecho Penal-parte general, t.II, p. 7.

${ }^{24}$ PIARENGELI, José Henrique. O consentimento do ofendido na teoria do direito.São Paulo: Revista dos Tribunais, 2008 , p.62.

${ }^{25}$ SAINZ CANTERO, José A. Lecciones de Derecho Penal, Parte General. Mexico: Editorial Bosch, v. III/3, p.256.

${ }^{26}$ Ver a propósito, People. v. Kimura (1985): People v. Wu (i991); People v. Nguyen

${ }^{27} \$ 17$. Error de prohibición

Sí le falta al autor en la comisión de un hecho la comprensión de lo injusto de su actuar entonces actúa sin culpa si el no pudo evitar ese error. Si el autor pudo evitar el error, entonces puede atenuarse la pena conforme al $₫ 49$, inciso 1 .
} vol.08, nº. 02, Rio de Janeiro, 2015. Pp. 758-773 
Conforme preleciona João Mestieri a possibilidade de entender o caráter ilícito (criminoso) do fato é genuinamente normativa, pois não se trata do conhecimento da ilicitude (operação de natureza psicológica), mas da mera possibilidade concreta desse conhecimento. $\mathrm{O}$ juízo de reprovação apenas se torna possível quando se constata que o agente teve, no caso específico, a possibilidade concreta de entender o caráter criminoso do fato praticado e assim determinar o seu comportamento de acordo com os interesses do sistema jurídico. O erro sobre a ilicitude do fato é erro de proibição; dá-se quando o agente por ignorância (ignorantia iuris) ou por uma representação falsa ou imperfeita da realidade supõe ser licito o seu comportamento. ${ }^{28}$

A diferença fundamental entre consciência real e consciência potencial reside no fato de que, naquela, $o$ agente deve, efetivamente, saber que a conduta que pratica é ilícita; na consciência potencial, basta a possibilidade que o agente tinha, no caso concreto, de alcançar esse conhecimento. Segundo Sanzo Brodt, "conforme a concepção finalista da teoria do delito, à reprovação penal não é necessária a atual consciência da ilicitude; basta a possibilidade de obtê-la. Daí conceituarmos consciência da ilicitude como a capacidade de o agente de uma conduta proibida, na situação concreta, apreender a ilicitude de seu comportamento. ${ }^{29}$ Cezar Roberto Bitencourt,assinala que com a evolução do estudo da culpabilidade, não se exige maisa consciência da ilicitude, mas sim a potencial consciência. Não mais se admitem presunções irracionais, iníquas e absurdas. Não se trata de uma consciência técnico-jurídica, formal, mas da chamada consciência profana do injusto, constituída do conhecimento da anti-socialidade, da imoralidade ou da lesividade de sua conduta. E, segundo os penalistas, essa consciência provém das normas de cultura, dos princípios morais e éticos, enfim, dos conhecimentos adquiridos na vida em sociedade. São conhecimentos que, no dizer de Binding, vêm naturalmente com o ar que a gente respira". ${ }^{30}$

Outrossim, não é necessária uma internalização das normas vigentes numa determinada sociedade, mas sim a falta de compreensão dos valores que esta encerra.Neste prisma, Maria Fernanda Palma, ensina que existe uma conjugação entre valores universais e uma ética das emoções construída ao longo da vida do próprio agente, de forma a satisfazer aquilo que ele tem para si como uma vida boa, a verdade é que neste caso o princípio da desculpa teria de intervir, uma vez que a força que é criada sobre o agente pela norma costumeira é de tal forma forte e irresistível, que o agente não pode ser julgado ou culpado por a seguir, pois nem sequer tem hipótese de conceber outra forma de agir, não passando sequer pela cabeça dos mesmos motivarem-se pelas normas em vigor

\footnotetext{
${ }^{28}$ MESTIERE,João.Manual de Direito penal-parte geral v. I, Rio de Janeiro: Forense, 1999., p. 168.Cf a respeito do tema: Maria Fernanda Palma "O princípio da desculpa em Direito Penal", edições Almedina, 2005; Figueiredo Dias "Liberdade - Culpa - Direito Penal", 3a Edição, 1995; Claus Roxin "Problemas fundamentais de direito" 3a ed. -Lisboa,1998; Augusto Silva Dias "Delicia in se e Delicta mera prohibita, uma análise das descontinuidades do ilícito penal moderno à luz da reconstrução de uma distinção clássica"(dissertação), 2004.

${ }^{29}$ SANDRO BRODT, Luis Augusto. Da consciência da ilicitude no direito penal brasileiro. Belo Horizonte: Del Rey,2001, p.46.

${ }^{30}$ BITTENCOURT, Cezar Roberto. Manual de Direito Penal. Parte geral.São Paulo, Saraiva, 2000, p.326-327.
} vol.08, nº. 02, Rio de Janeiro, 2015. Pp. 758-773 
na comunidade de destino. ${ }^{31}$ Outro ponto, a ser analisado, é o sugerido por Augusto Silva Dias, à pessoa do tipo social do agente. Através deste conceito podemos analisar se o agente poderia, através de um esforço reflexivo, atingir a consciência da ilicitude, recorrendo para tanto, o grau de integração efectiva do agente na sociedade. ${ }^{32}$

Por fim teremos o teste do "homem medio", no caso dos crimes culturalmente motivados, ou seja,se é possivel exigir-se o dever de cuidado do homem medio, do homem homo medius,do tipo comum de sensibilidade ético-social. ${ }^{33}$

\title{
CONCLUSÃO
}

Embora pouco utilizada no Brasil, mas largamente utilizada nos Estados Unidos e Europa, por força das imigrações, o Brasil de hoje já é visto como terra de oportunidades, e até mesmo mais atrativo aos estrangeiros que os países do primeiro mundo, cujas legislações anti-imigrantes tem endurecido ao longo do tempo. È legitima a utilização da Defesa Cultural, tendo em vista o novo contexto histórico e sociocultural do Brasil e de seus novos imigrantes.

\section{THE CULTURAL DEFENSE IN THE SCOPE OF CRIMINAL LAW AND CRIMINAL PROCEDURE: A COMPARATIVE LAW VISION AS PARADIGM FOR APLICATION AT THE BRAZILIAN LAW}

\begin{abstract}
The right to culture, though rarely explicitly found in the legal order is a fundamental right which is guaranteed by international law and finds its strongest wording of Article 27 of the International Covenant on Civil and Political Rights, incorporating thus treated about human rights. The Universal Declaration on Cultural Diversity, UNESCO, we find the affirmation of the cultural identity of each group, be it politically sovereign or not, is a great power or not fully available resources and techniques or that is still in development, is the foundation of cultural pluralism. Recognition and respect for such pluralism, equal rights and dignity, appear today as a factor of peace and understanding between nações.A idea that cultural pluralism could be the "very essence of cultural identity" questions the traditional image of States, culturally monolithic and introduces the notion of "culture of miscegenation," he came to the conclusion that "the cultural diversity of people should be considered as a factor of balance and not division". The UNESCO recognizes that Culture takes diverse forms across time and space. This diversity is embodied in the uniqueness and plurality of the identities of the groups and societies making up humankind. This article deals with the relationship between the right to culture and the relevant aspects of cultural defense in order, especially the doctrine and case law already formed in Law Internacional.O right to culture is a

\footnotetext{
${ }^{31}$ PALMA, Fernanda Maria. O princípio da desculpa em direito penal. Almadina, 2005, p.231.

32 DIAS, Augusto Silva. "Delicta in se" e "delicta mera prohibita", uma analise da reconstrução de uma distinção clássica (dissertação), 2004, p.221.

${ }^{33}$ HUNGRIA, Nelson. Comentários ao Código Penal, v. I, t, II. Rio de Janeiro: Forense, 1969.p. 188. vol.08, nº. 02, Rio de Janeiro, 2015. Pp. 758-773
\end{abstract}


source of exchange, innovation and creativity and cultural diversity is for mankind, as necessary as biodiversity is for nature.

Keywords: Culture. Cultural Defenses. Legal Pluralism. Universalism. Multicultural Society. Cultural Tradition. Immigrants. Migration Cultural. Defense.

\section{BIBLIOGRAFIA}

BASILE, Fábio. Imigrazioni e reati culturalmente motivati. il diritto penale nelle società multicultural. Milano: Giuffrè editore 2010.

BITTENCOURT, Cezar Roberto. Manual de Direito Penal.Parte geral. São Paulo,Saraiva.2009.

BRONITT, Simon. Visions of a Multicultural criminal law: an Australian perspective. In: Multicultural jurisprudence. Comparative perspectives on the cultural defense.

CANTERO, José A. Sainz. Lecciones de Derecho Penal. México: Editorial Boshi.Parte General, v. III/3.

CURI ÚRZÚA, Enrique. Derecho Penal - parte general. Editorial Jurídica de Chile,V.II.

DIAS, Augusto Silva. Delicia in se e Delicta mera prohibita, uma análise das descontinuidades do ilícito penal moderno à luz da reconstrução de uma distinção clássica (dissertação), 2004.

DIAS, Figueiredo. Liberdade - Culpa -Direito Penal. Coimbra: Coimbra editora. 3a Edição, 1995.

DUNDES, Renteln Alison. The Cultural Defense. New York: Oxford University Press, 2004.

BRONITT, Simon. Visions of a Multicultural criminal law: an Australian perspective. In: Multicultural jurisprudence. Comparative perspectives on the cultural defense. FOBLETS, Marie-Claire; RENTEELN, Alison Dundes (Ed.). Oregon: Oxford and Portandle, 2009.

HÖFFE, Otfried. Globalizzazione e diritto penale. Torino, Edizioni di Comunità (Territori di Comunità, 24), 2001.

HUNGRIA, Nelson. Comentários ao Código Penal, v. I,t, II. Rio de Janeiro: Forense.1969.

MESTIERE, João. Manual de Direito penal-parte geral, v. I,Rio de Janeiro: Forense, 1999.

PALMA, Maria Fernanda. O princípio da desculpa em Direito Penal. Edições Almedina, 2005.

PIARENGELI, José Henrique. O consentimento do ofendido na teoria do direito. São Paulo: Revista dos Tribunais, 2008.

ROXIN, Claus. Problemas fundamentais de direito. $3^{\text {a }}$ ed. - Vol. II. Lisboa: Universidade de Direito e Ciência Jurídica, 1993.

SANDRO BRODT, Luis Augusto. Da consciência da ilicitude no direito penal brasileiro. Belo Horizonte: Del Rey, 2001. 
WELZEL, Hans. Derecho penal alemão. Chile: Juridica de Chile,1987.

ZAFFARONI, Raúl Eugenio et al. Criminalidad, evolución del derecho penal y crítica al derecho penal en la acutalidad. Buenos Aires: Del Puerto, 2009.

Trabalho enviado em 20 de janeiro de 2015.

Aceito em 26 de março de 2015. 